\title{
Consortium for Petroleum \& Natural Gas Stripper Wells
}

\author{
Technical Quarterly Progress Report for \\ February 1, 2007 - March 31, 2007
}

By

Joel L. Morrison

and

Sharon L. Elder

June 22, 2007

Work Performed Under DOE Cooperative Agreement DE-FC26-04NT42098

\section{Submitting Organization:}

The Pennsylvania State University

The Energy Institute

C211 Coal Utilization Lab

University Park, PA 16802 


\section{DISCLAIMER}

This report was prepared as an account of work sponsored by an agency of the United States Government. Neither the United States Government nor any agency thereof, nor any of their employees, makes any warranty, express or implied, or assumes any legal liability or responsibility for the accuracy, completeness, or usefulness of any information, apparatus, product, or process disclosed, or represents that its use would not infringe on privately owned rights. Reference herein to any specific commercial product, process, or service by trade name, trademark, manufacturer, or otherwise does not necessarily constitute or imply its endorsement, recommendation, or favoring by the United States Government or any agency thereof. The views and opinions of the authors expressed herein do not necessarily state or reflect those of the United States Government or any agency thereof. 


\section{ABSTRACT}

The Pennsylvania State University, under contract to the U.S. Department of Energy (DOE), National Energy Technology Laboratory (NETL), established a national industrydriven Stripper Well Consortium (SWC) that is focused on improving the production performance of domestic petroleum and/or natural gas stripper wells. The SWC represents a partnership between U.S. petroleum and natural gas producers, trade associations, state funding agencies, academia, and the NETL.

This document serves as the twelfth quarterly technical progress report for the SWC. Key activities for this reporting period included:

- Drafting and releasing the 2007 Request for Proposals;

- Securing a meeting facility, scheduling and drafting plans for the 2007 Spring Proposal Meeting;

- Conducting elections and announcing representatives for the four 2007-2008 Executive Council seats;

- 2005 Final Project Reports;

- Personal Digital Assistant Workshops scheduled, and

- Communications and outreach. 


\section{TABLE OF CONTENTS}

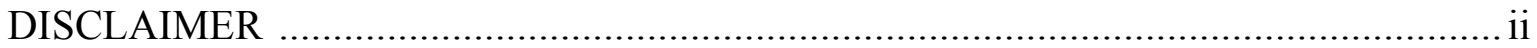

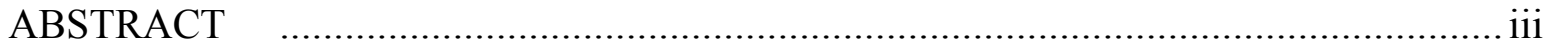

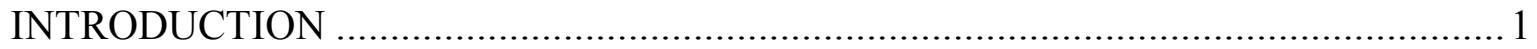

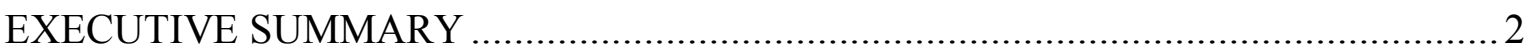

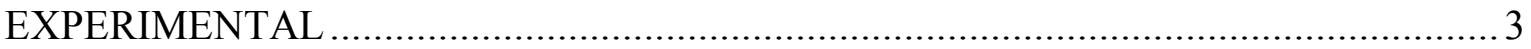

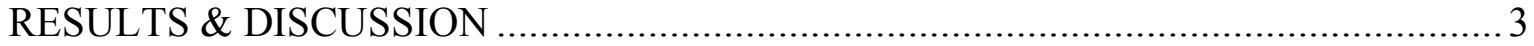

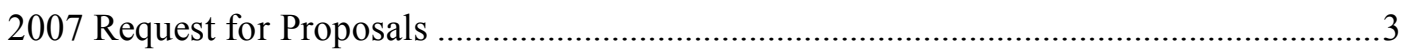

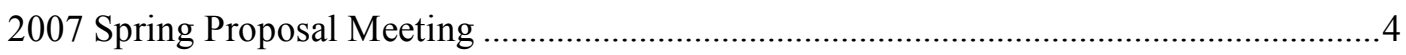

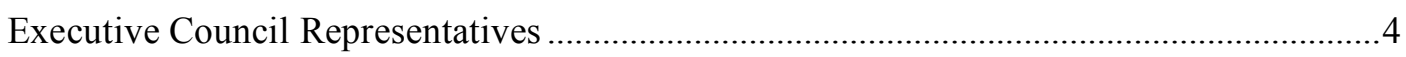

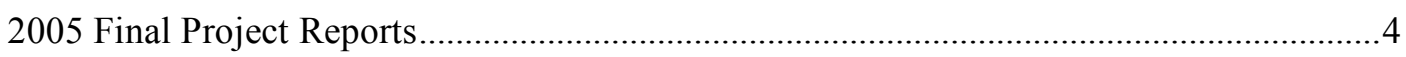

Personal Digital Assistant Workshop Notice ....................................................................

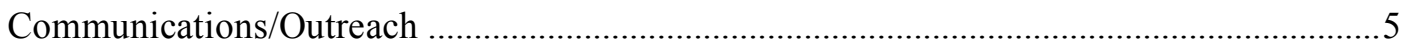

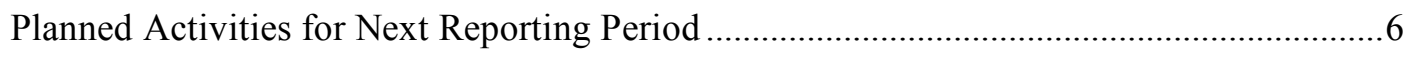

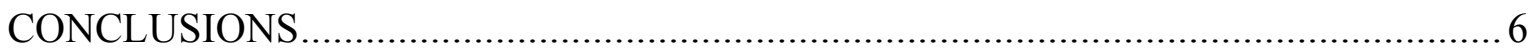

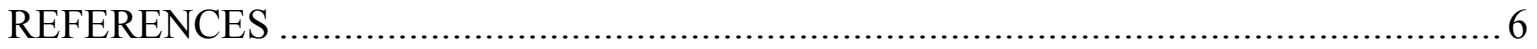

APPENDIX

Appendix A - Request for Proposals ...................................................... 8 


\section{INTRODUCTION}

The Pennsylvania State University, under contract to the U.S. Department of Energy (DOE), National Energy Technology Laboratory (NETL), established an industry-driven Stripper Well Consortium (SWC) that is focused on improving the production performance of domestic petroleum and/or natural gas stripper wells. Industry-driven consortia provide cost-efficient vehicles for developing, transferring, and deploying new technologies in the private sector. The SWC represents a partnership between the U.S. petroleum and natural gas industries and trade associations, state funding agencies, academia, the NETL, and the National Petroleum Technology Office.

The SWC technology development research is conducted in the areas of reservoir remediation, wellbore cleanup, and surface system optimization. Projects are funded on an annual basis. SWC members elect an Executive Council that is charged with reviewing projects for co-funding. Proposals must address improving the production performance of stripper wells and provide significant cost sharing. The process of having industry members develop, review, and select projects for funding ensures the SWC conducts research that is relevant and timely to the industry. Co-funding of projects using external sources of funding is sought to ensure that SWC funds are highly leveraged. 
This report summarizes important accomplishments during the period of February 1, 2007, through March 31, 2007. This is the twelfth quarterly report since the inception of the SWC on September 30, 2000. The SWC was established under contract to The Pennsylvania State University from the U.S. Department of Energy (DOE), National Energy Technology Laboratory (NETL). The agreement provides The Pennsylvania State University with the overarching management responsibilities for the SWC.

Key activities for this reporting period included the following:

Request for Proposals Drafted and Released

The 2007 Request for Proposals was drafted and released with proposals due on May 8, 2007.

\section{Spring Proposal Meeting}

The Spring Proposal Meeting to hear all requests for funding will be held on May 2223, 2007 at the Inn on the Lake, Canandaigua, NY. In addition to hearing proposal requests, a strategic planning session is planned.

\section{Executive Council Representatives}

The SWC Technical Advisory Committee elected four (4) representatives to serve on the Executive Council for 2007-2008. The new representatives will join the three council members who will serve until the end of 2007.

\section{SWC Final Project Reports}

The 2005 Final Project Reports are due and scheduled for distribution during the next quarter. During this quarter, ten reports were received and approved.

\section{Personal Digital Assistant Workshop Notice}

The Personal Digital Assistant Software Program for Pumpers/Well Tenders Workshop notice was distributed by the Oklahoma Marginal Well Commission for four (4) training programs during May 2007. The registration form for the workshop is available on the MWC website.

\section{Communications/Outreach}

The SWC Insider e-newsletter was drafted for release in April 2007. The enewsletters are distributed to the SWC listserve and posted on the SWC website. Two 2006 SWC projects appeared in the GasTIPS, Volume 13, Number 1, 2007 edition. Distribution of the public broadcast documentary video, "Independent Oil: Rediscovering America's Forgotten Wells," continues. The project quarterly and final reports are posted in the "members only" portion of the SWC web page, as received. 
A description of experimental methods is required by the DOE for all quarterly technical progress reports. In this program, Penn State is responsible for establishing and managing the industry-driven SWC. Technology development research awards are made on a competitive basis. Therefore, this section is not applicable to Penn State's contracted activities. Technical reports from the individual researchers are required to contain experimental discussion sections and are submitted to SWC members and the DOE for review.

\section{RESULTS AND DISCUSSION}

This report addresses the activities for the reporting period from February 1, 2007, through March 31, 2007. During this time period SWC efforts were directed toward the following activities:

- 2007 Request for Proposals;

- 2007 Spring Proposal Meeting planning;

- Election of four (4) Executive Council representatives;

- 2005 Final Project Reports;

- PDA Workshop Notice; and

- Communications/outreach.

\section{Request for Proposals}

The 2007 Request for Proposals (RFP) was drafted and released for proposals due May 8, 2007. Proposals that will have the potential to significantly improve the production from domestic petroleum and natural gas stripper wells or fields, significantly reduce operator costs, or improve the environmental issues typically associated with stripper well operations are requested. Proposals are being solicited from all current Full and Supporting Members in the following research focus areas:

- Reservoir remediation, characterization, and operations

- Well-bore clean-up

- Surface and collection optimization 
The funding cycle for selected proposals will be from August 1, 2007 to July 31, 2008. The RFP is attached as Appendix A.

\section{Spring Proposal Meeting}

The 2007 Spring Proposal Meeting to hear all proposals received in response to the RFP will be May 22-23, 2007 at the Inn on the Lake, Canandaigua, New York. In addition to presentations from all project submissions, a strategic planning session is planned. The preliminary plans for the meeting are drafted and a final agenda will be completed during next quarter.

\section{Executive Council Representatives}

The SWC conducted elections for four (4) candidates to serve on the Executive Council for 2007-2008. The new representatives are:

- James Ashbaugh, Pennsylvania General Energy Co, LLC

- Dee Combs, Chesapeake Energy-Eastern Division

- William Fustos, East Resources, Inc.

- John Holko, Lenape Resources, Inc.

The Executive Council members who will continue to serve until the end of 2007 are:

- Len Paugh, Great Lakes Energy Partners, LLC

- Robert Metzgar, North Penn Pipe \& Supply, Inc.

- Paul Willhite, University of Kansas

\section{Final Project Reports}

The 2005 projects ended December 31, 2006. All final reports are now due and are being collected for distribution to all 2005 Full members. To date, ten reports have been received, approved, and are posted in the "members only" portion of the SWC website. The final reports will be distributed in mid-summer.

\section{Personal Digital Assistant Workshop Notice}

The Personal Digital Assistant (PDA) Software Program for Pumpers/Well Tenders Workshop Notice has been distributed by the Oklahoma Marginal Well Commission. The registration form for this 2006 SWC project is available on the website at: http://www.marginalwells.com. The program was designed by Mr. Josh Cook, Cook Contracting LLC to give small producers the opportunity to have pumper/well tenders 
gather basic information from the field and enter it into a small handheld device. The information can then be entered into a main database on a home office computer to show a history of the well's production in different forms. The program is capable of storing information including: volume of production in feet and inches, equipment on site, chemicals, meter readings, pressure readings, gauge measurements, several note fields, as well as the ability to perform simple calculations, such as Bbl./in. tank volume conversion, gas volume, and strokes per minute. The training program includes four (4) workshops opportunities: May 15 in Enid, OK; May 16 in Tulsa, OK; May 17 in Oklahoma City, OK, and May 18 in Ardmore, OK.

\section{Communications/Outreach}

The SWC continues to promote itself in many ways via electronic news, magazine articles, sponsoring technical sessions, distributing Public Broadcasting Corporation documentary videos, promotional packets, telephone follow-up to inquiries, presentations, and participating in trade shows and expositions.

Two projects appeared in GasTIPS, Volume 13, Number 1, 2007: Uncovering Bypassed Pay in Central Oklahoma Using Statistical Analysis and Field Tests (Schlumberger Consulting Services), pp. 2-5 and Oklahoma Commission on Marginally Producing Oil and Gas Wells (Oklahoma Marginal Well Commission), pp. 18-20.

The notice of proposal solicitation appeared in the PTTC Tech Alert e-news on March 9, 2007 under DOE Highlight: Stripper Well Consortium Seeks Proposals due May 8.

Distribution of the PBS documentary video, "Independent Oil: Rediscovering America's Forgotten Wells" continues.

The electronic newsletter, the SWC Insider was drafted for release in April 2007. The newsletter will be sent to everyone on the SWC listserv and posted to the SWC Web site.

The SWC web site (http://www.energy.psu.edu/swc) continues to be updated. The "members only" portion of the Web site is now operational; and houses all information not available for public viewing, including all project quarterly and final reports, project 
abstracts, etc.

\section{Planned Activities for Next Reporting Period}

During the next quarter the SWC will:

- Complete the final plans and conduct the 2007 Spring Proposal Meeting;

- Identify projects for 2007 and issue award letters;

- Compile and release the 2005 SWC Final Project Reports;

- Continue new member recruitment;

- Draft and release another online newsletter; and

- Continue to update and improve the SWC Web site.

\section{CONCLUSIONS}

During this reporting period, the SWC released the 2007 Request for Proposals. The meeting site to hear all proposal requests was identified and an agenda drafted. The SWC elected four representatives to serve on the Executive Council for 2007-2008. The 2005 final project reports are being compiled. The 2006 PDA Project has scheduled four workshops in Oklahoma to train pumper/well tenders. Two articles on SWC research activities appeared in GasTIPS, Volume 13, Number 1. 2007. Through these efforts, the SWC has laid a solid foundation for continued membership growth and industry-relevant technology transfer.

\section{REFERENCES}

A listing of referenced materials is required by the DOE for each quarterly technical progress report. However, this technical progress report for the SWC did not utilize any reference materials. 
APPENDIX A

Request for Proposals 


\title{
The \\ Stripper Well Consortium
}

Request for Proposals

For 2007

\author{
Submission Deadline: \\ May 8, 2007 (4:00 pm EST)
}




\section{REQUEST FOR PROPOSALS \\ FOR THE STRIPPER WELL CONSORTIUM}

\section{APPLICANT ELIGIBILITY}

Competition for the Stripper Well Consortium (SWC) funding is open to all current Full and Supporting Members. Proposals submitted by parties not having a current Consortium membership agreement in place will be returned without review.

\section{INSTITUTION COMMITMENT}

Each proposal must be signed by an official of the company or university who is authorized to commit the company/institutional resources to the project. The name of the Applicant's authorized official shall be entered in the appropriate space shown on the cover page (Attachment B).

\section{RESEARCH FOCUS AREAS}

The mission of the SWC is to assist in the development, demonstration, and commercialization of technologies to improve the production performance of the nation's natural gas and petroleum stripper wells. Proposals are being solicited from the SWC Full and Supporting Members in the following three focus areas:

\section{Reservoir remediation, characterization, and operations}

Examples include, but are not limited to, the identification of by-passed reservoirs/ zones, stimulation/ recompeletion of existing wells, and mitigation/ reduction of water production

\section{Well-bore clean-up}

Examples include, but are not limited to, dewatering, down hole separation and injection, and removal of solids such as salts, scale, and hydrocarbon precipitation.

\section{Surface and collection optimization}

Examples include, but are not limited to, disposal/ utilization of solid-liquid waste streams (e.g. brine), surface treatment/ measurement of gas, and pipeline usage/ maintenance and compression.

In 2007, the SWC is seeking to identify new technologies that will have the potential to significantly improve the production from domestic petroleum and natural gas stripper wells or fields, significantly reduce operator costs, or improve the environmental issues typically associated with stripper well operations. Such technologies should have broad applicability to large regions of the U.S. rather than benefit any one single operator. 


\section{AWARDS}

Awards will be made on an annual basis. Subcontracts will be issued from The Pennsylvania State University to the successful applicant. The period of performance for the 2007 funding cycle will be from August 1, 2007 to July 31, 2008. Members will be permitted to submit future proposals to extend the proposed work; however, this must be performed on an annual basis.

If additional documentation is required prior to issuance of a subcontract, a delay in submission of the August 1 start date may occur.

\section{SUBMISSION}

The deadline for receipt of SWC proposals is May 8, 2007 by 4:00 PM (Eastern

Standard Time). Proposals submitted after the deadline will be returned to the applicant without being reviewed. Applicants are to refer to Appendix A (Proposal Checklist) to ensure that their proposal packet is complete. The proposal packet should be submitted to the following address:

Mr. Joel L. Morrison

Director, Stripper Well Consortium

The Pennsylvania State University

C-211 Coal Utilization Laboratory

University Park, PA 16802-2323

In addition to the proposal, each applicant is required to provide the SWC membership with a nominal fifteen (15) minute presentation on the proposed project at the SWC Spring Meeting. The SWC will hold its 2007 Spring Meeting in Canandaigua, New York on May 22-23, 2007. Applicants are required to provide their presentation with the submittal of their proposal.

\section{PROPOSAL FORMAT}

The format for your SWC proposal follows. The proposal should be on standard 8 1/2" x 11" letter size paper with 1" margins, each copy to be three hole punched and clipped. Please do not staple the proposal. Each page of the proposal should be numbered at the bottom. The type size must be clear and legible, in standard size, 12 points. No smaller than 10 point font size will be accepted with double line spacing. 


\section{SECTIONS OF THE PROPOSAL}

The proposal shall consist of the following sections in order.

\section{Proposal Checklist See Attachment A}

The proposal checklist is required to ensure the proposal submittal is complete and that the applicant is eligible for Consortium funding consideration.

\section{Cover Sheet See Attachment B}

The cover sheet along with the executive summary will be distributed to the SWC membership as part of the proposal evaluation process.

\section{Table of Contents One (1) page maximum}

\section{Public Executive Summary One (1) page maximum}

Provide a one-page summary of the proposed research. The executive summary should not contain any propriety or business sensitive data because summary will be distributed to the SWC membership along with the proposal cover sheet. An electronic copy of the executive summary is required. The summary will be posted to the SWC and/or program sponsor websites if the Consortium funds the proposal. The summary should be written in the third person and include a statement of objectives and methods to be employed. It should be informative to other persons working in related fields and understandable to a scientifically or technically literate lay reader.

\section{Technology Overview One (1) page maximum}

The technology overview section of the proposal enables the applicant to discuss how their proposed technology is different from existing technology that may be available within the industry. At a minimum the following should be discussed:

- Is the technology covered by existing patents, and if so, what are they; and

- How does the proposed technology differ from existing technology?

\section{Project Description Five (5) page maximum}

The main body of the proposal should outline the plan of work, including the broad design of activities to be undertaken. At a minimum, the following should be discussed:

- Statement of the problem;

- Has the proposed work, or a portion of the proposed work, been funded elsewhere;

- Objectives and expected significance of the research;

- Statement of the work plan;

- Relation of the proposed work to comparable work in progress;

- Description of available facilities and major items of equipment available for the work; and reference citations. 


\section{Project Schedule One (1) page maximum}

A plan that establishes the time schedule for accomplishing the proposed work. The plan should include major milestones of the project in bar chart format and should cover the complete period of performance.

\section{Anticipated Results $\quad$ Two (2) page maximum}

Discuss how the proposed work will help the U.S. stripper well industry and the eventual adoption of the proposed work by industry. At a minimum, the following should be discussed:

- How will the proposed technology significantly improve the production of a given well or region, significantly reduce operating costs, or improve the environmental issues associated with stripper wells;

- What is the commercialization viability of the proposed research; and

- Identify any specific groups that will use the projected results.

\section{Previous SWC-Funded Projects One (1) page maximum/ project}

If the applicant has been awarded SWC-funding in previous years, the applicant is required to provide a brief summary of those projects for review. The summary for each project should not exceed one page and should contain the following:

- Project title

- Total level of funding (SWC funding and applicant cost share)

- Description of how it has benefited the U.S. stripper well industry.

- List of companies and key contact information for those using the previously funded project results.

\section{Budget See Attachment C}

The submission of a reasonable budget is an important part of the proposal. Your budget may request funds under any of the categories listed on Attachment $\mathrm{C}$ provided that the item and amount are considered necessary to perform the work. Proposed equipment expenditures must be justified and are subject to program sponsor approval.

\section{Cost-Share Commitments}

A minimum of $30 \%$ cost-share is required. Applicants are encouraged to provide more than $30 \%$ cost share. The Executive Council will be tracking the level of cost share provided in each project. Cost share, which may be in the form of cash and third party in-kind, are acceptable as part of the matching if they meet the following criteria:

- Are verifiable, necessary and reasonable for proper and efficient accomplishment of the project;

- Are incurred within the project performance period, previously expended research, development, or exploration costs are unallowable.

- Are not included as contributions for any other federal project, are not paid by the Federal Government under another award, and be otherwise allowable in accordance with applicable Federal cost principles and DOE regulations governing cost sharing.

Visit the SWC web site - http://www.energy.psu.edu/swc to download this and other SWC documents. Last modified on March 5, 2007 
- The value of patents and data contributed to the project is unallowable as cost sharing.

All cost-sharing commitments must be supported by appropriate documentation. Failure to provide appropriate documentation can result in the proposal being returned without review.

\section{Biographical Sketches One (1) page per person maximum}

Each vitae should include educational background, professional experience, research interest, honors and professional activities.

\section{Project Team One (1) maximum}

All collaborations with individuals not included in the budget should be described and documented with a letter from each collaborator.

\section{Letters of Support}

Letters of support from outside sources are encouraged.

\section{TREATMENT OF PROPRIETARY INFORMATION}

Privileged or confidential commercial or financial information that the applicant does not want disclosed to the public or used by the Government for any purpose other than application evaluation, should be specifically identified by page on the proposal cover sheet.

\section{PROPOSAL EVALUATION PROCESS}

The SWC Executive Council will review and select projects for SWC funding. The SWC Director will notify all applicants within thirty (30) days of the SWC Executive Council meeting, by letter, of the final decision regarding their proposals. The decision of the Executive Council is final and not subject to reconsideration or appeal.

\section{REALLOCATION OF FUNDS/ PROJECT MODIFICATIONS}

Recipients of SWC Awards will have substantial discretion to reallocate funds should changing conditions demand it. Requests for budget revisions and/or project extensions shall be submitted in writing to the SWC Director.

\section{ADDITIONAL INFORMATION}

Additional questions should be forwarded to the SWC Director. Questions should be submitted via e-mail to swc@ems.psu.edu or contact Mr. Joel Morrison at (814) 8654802. 


\section{ATTACHMENT A - PROPOSAL PACKET CHECKLIST}

I certify that:

\section{$\square$ I am a current Full member of the Stripper Well Consortium $\square$ I am a current Supporting member of the Stripper Well Consortium}

Project Title:

Principal Investigator (PI):

To assure that your application is complete, please complete and paper clip (one copy only) the proposal packet checklist to the cover sheet of the original (signed) copy of the proposal. Be sure the following items are included in the following order.

Cover page completed and signed by PI and authorized representative

Public Executive Summary (one page maximum)

Technology Overview (one page maximum)

Project Description (five page maximum)

Project Schedule (one page maximum)

Anticipated Results (two page maximum)

Previous SWC-Funded Projects (one page maximum/ project)

Budget (Using Attachment $\mathrm{C}$ budget template)

Cost-Share Commitments

Biographical Sketches (one page/ person maximum)

Project Team (one page maximum)

Letters of Support

Required number of copies (original +12 copies)

Electronic copy of proposal (pdf, if possible)

Electronic copy of the Public Executive Summary (pdf, if possible)

Proposal presentation (15 minute presentation, PowerPoint encouraged)

Visit the SWC web site - http://www.energy.psu.edu/swc to download this and other SWC documents. Last modified on March 5, 2007 


\section{ATTACHMENT B - PROPOSAL COVER SHEET}

Proposal Submitted to:

Mr. Joel Morrison

Director, Stripper Well Consortium

The Pennsylvania State University

C-211 Coal Utilization Laboratory

University Park, PA 16802-2308

Proposal Deadline: $\quad$ May 8, 2007 (4:00 PM EST)

Date of Submission

Title of Proposal:

Company Name:

Principal Investigator:

Phone:

Fax:

Email

Address:

Other Participants:

Amount Requested from SWC

Cost Share Commitments

(Minimum 30\% Required)

Total Project Costs
$\$$

Cash \$

In-Kind

$\$$

$\$$ 
PROPRIETARY INFORMATION: Does this proposal contain Proprietary or Confidential Information?

NO YES (if yes, complete box below)

\section{Notice of Restrictions on Disclosure and Use of Data}

The data contained on pages of this proposal are submitted in confidence and contain privileged or confidential commercial and/or financial information. Such data may be used or disclosed only for evaluation purposes. If funded, the Government would have the right or use or disclose data from this project to the extent provided the DOE/PSU Cooperative Agreement. This restriction does not limit the Government's right to use or disclose data obtained without restrictions from any source, including the proposer.

Submitted by:

Signature of PI
Approved by:

Authorized Representative 


\section{ATTACHMENT C - BUDGET}

$\underline{\text { Salaries and Wages }}$

List individually all personnel identified in the proposal.

Include title and percent of effort

NOTE: The use of undergraduate and graduate students is encouraged, and appropriate.

The basis for proposed percent of effort or labor hours should be identified (historical hours, engineering estimates).

Fringe Benefits

Materials and Supplies

List types required and estimated costs.

NOTE: State whether amounts proposed are based on catalog prices or other cost estimating.

\section{Equipment}

Items exceeding $\$ 5,000$ and 1 year's useful life are defined as permanent equipment. List item and dollar amount for each amount. Justify and/or provide quotation.

Travel (see Note 4)

State the type and extent of travel and its relation to the project. Itemize by destination and estimated costs.

Publication/Information Dissemination Estimate costs of documenting, preparing, publishing and sharing research findings. Show estimates.

Other Direct Costs Itemize and justify. $(*$ See note below)

\section{Facilities and Administration (F\&A)}

Specify current rate(s) and base.

Note: A copy of the negotiated agreement should be included with the proposal. If none exists, a disclosure of the contents of the rate should be made.
$\$$

Name of PI:

$\$$

$\$$

$\$$

$\$$

$\$$

TOTALS

\section{Attach up to two additional pages of justification covering all items.}

Visit the SWC web site - http://www.energy.psu.edu/swc to download this and other SWC documents. Last modified on March 5, 2007 


\section{*NOTES:}

1) If more than $5 \%$ of project cost is from SWC funding the contracting organization must be a Full or Supporting Member of the SWC.

2) Subcontracts to current consortium members must be less than $50 \%$ of the requested SWC funding. Budgets and work statements from each subcontractor, in the format above, should be included.

3) Fees or profits will not be paid on any award resulting from this solicitation. Nor can fee or profit be considered as cost-sharing.

4) The SWC is planning to host two technology transfer workshops during the last quarter of 2007 and 2008 . The workshops will be held in the eastern (Pennsylvania/ New York/ West Virginia region) and southern/ western US (Oklahoma/ Colorado region). Recipients of SWC funding may be required to provide a presentation on the status of their project at both the eastern and southern technology transfer meetings if requested. The costs of attending these SWC technology transfer meeting are to be included in the travel budget. Supporting members are required to pay a meeting registration fee for these meetings.

Visit the SWC web site - http://www.energy.psu.edu/swc to download this and other SWC documents. Last modified on March 5, 2007 